Article

\title{
An Arc Furnace as a Source of Voltage Disturbances-A Statistical Evaluation of Propagation in the Supply Network
}

\author{
Ryszard Klempka (D)
}

check for updates

Citation: Klempka, R. An Arc Furnace as a Source of Voltage Disturbances-A Statistical Evaluation of Propagation in the Supply Network. Energies 2021, 14, 1076. https://doi.org/10.3390/ en14041076

Academic Editor: Andreas Sumper

Received: 23 December 2020

Accepted: 16 February 2021

Published: 18 February 2021

Publisher's Note: MDPI stays neutral with regard to jurisdictional claims in published maps and institutional affiliations.

Copyright: (C) 2021 by the author. Licensee MDPI, Basel, Switzerland. This article is an open access article distributed under the terms and conditions of the Creative Commons Attribution (CC BY) license (https:/ / creativecommons.org/licenses/by/ $4.0 /)$.
Faculty of Electrical Engineering, Automatics, Computer Science and Biomedical Engineering, AGH-University of Science and Technology, 30-059 Krakow, Poland; klempka@agh.edu.pl

\begin{abstract}
This article presents the results of measuring $P_{s t}$ indicators at three points of a power system supplying a large source of voltage disturbances - an arc furnace. Measurements were made at three voltage levels: 30,110 , and $400 \mathrm{kV}$. Recorded values of $P_{\text {st }}$ at each point were subjected to statistical analysis, the probability distributions were adjusted to their histograms, and the nature of changes in the basic parameters of these distributions with the distance from the source of disturbances was indicated. The adjustments of the distributions were made using a modified firefly algorithm.
\end{abstract}

Keywords: power quality; flicker; arc furnace; voltage fluctuations

\section{Introduction}

Interest in the issue of power quality specified in the EN 50160 standard [1] is growing along with the development of the energy market. The rapid increase in the number of loads of different power and a different nature of work has highlighted their significant impact on the supply network, including the voltage itself. Voltage fluctuations can have economic and ergonomic effects. Therefore, there is a need to determine the impact of the load for voltage changes and the need to search for and indicate the load causing such changes [2-9]; thus, it is necessary to assess how voltage disturbances propagate through the energy system [10-13]. The most obvious point on which to focus is the registration of the voltage fluctuation index $P_{\text {st }}$ and correlating it with the parameters of the energy system. One should also remember what this measure is and how it is determined; it estimates the level of frustration of a statistical person with statistically healthy eyesight for changes in the brightness of the glow source caused by voltage changes [14]. There is no doubt, however, that the basic step to improve the power quality parameters is to find the source of the disturbances [2-9] and the secondary issue is to use some numerical measures that define voltage fluctuations. The basic indicator of voltage disturbances is $\mathrm{P}_{\text {st }}$, which has its drawbacks and so, often attempts are made to replace it or its estimation with other quantities that characterize the power system [15-26].

This article presents a statistical analysis of the propagation of voltage disturbances in a power system, the source of which is a large arc furnace. In the literature, the electric arc furnace is often cited as an example of the load causing voltage fluctuations [3,16,20,21,27] and other phenomena [28-30]. In this example, the arc furnace under examination is not the only source of disturbance, as there are more ladle and arc furnaces in the immediate vicinity, but this one furnace is clearly larger than the others and its influence is, therefore, clearly visible. In the arc furnace supply system, $P_{\text {st }}$ values were measured at three points and at different voltage levels. Technical documentation of the system was also available which made it possible to determine the equivalent impedance of the power system components, i.e., power lines, chokes, transformers, etc. Information on the short-circuit power of $400 \mathrm{kV}$ was also available. This parameter is sometimes difficult to estimate due to the unavailability of information and configuration changes occurring in the energy system itself, made during the use of the system [31]. 
The continuous development of science and technology creates new problems, the analytical solution for which becomes increasingly difficult or even impossible to establish due to mathematical knowledge or the time needed to determine the solution. Then, modern numerical optimization methods included in the group of artificial intelligence methods are involved, e.g., genetic algorithms, bees, fireflies, ants, particle swarms, cuckoos, gray wolves, and many others. Examples of their use in technical issues are already numerous [32-39] and for this article, a modified firefly algorithm was used [36,38,39].

\section{Analyzed Power Supply System}

The arc furnace is one of the most restless loads that deteriorates the power quality $[3,16,20,21,27]$. It is a source of reactive power, higher harmonics, and significant voltage fluctuation in the supply network, as measured by the $P_{s t}$ indicator.

In one Polish steel mill, the arc furnace was modernized, increasing its smelting capacity, i.e., its power was increased. This modernization was followed by the necessity to adapt the power supply system by adding a C-type second harmonic filter to the alreadyexisting third harmonic filters [28]. This resulted in a compensation of increased reactive power and reduction of harmonics below the limits indicated in EN 50160. Unfortunately, it was not possible to reduce the increased influence of the arc furnace on voltage changes in the distribution network. Therefore, it was decided to carry out further modernization of the power supply system by replacing some elements and connecting an SVC system (Static Var Compensator) [31]. In order to be able to assess the effectiveness of these changes, the quality parameters of the electricity were measured and the impact of the arc furnace on the supply network and the propagation of voltage disturbances was assessed by analyzing the $P_{\mathrm{st}}$ indicator before making the necessary changes. The arc furnace supply system is shown in Figure 1.

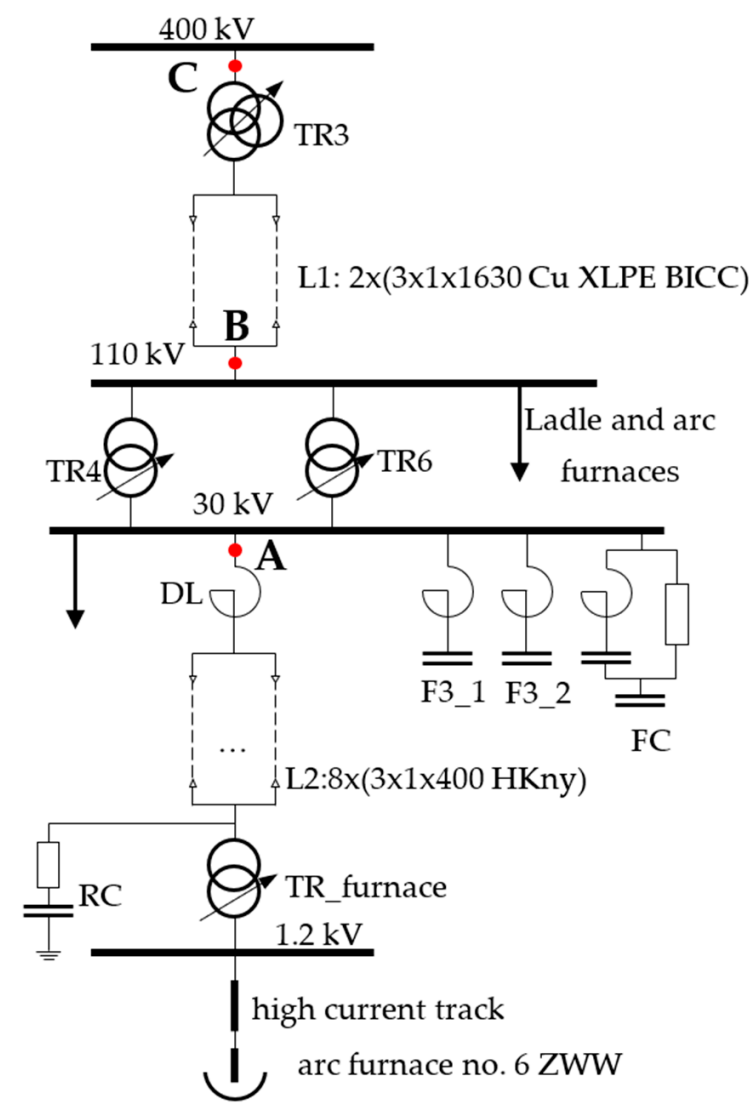

Figure 1. Scheme of the arc furnace power supply system with the selected measurement points. 
Measurements were made at the same time at three points of the power system (Figure 1) using Fluke1760 recorders:

- $\quad 400 \mathrm{kV}-\mathrm{C}$ point, above transformer TR3;

- $\quad 110 \mathrm{kV}-\mathrm{B}$ point, above parallel connected transformers TR4 and TR6;

- $30 \mathrm{kV}$-A point, above choke DL.

The measurements were performed with current transformers: 600/5, 1600/1, 3000/5 A and voltage transformers: $400 / 0.1,110 / 0.1,30 / 0.1 \mathrm{kV}$.

The main factor influencing the propagation of voltage disturbances in the supply system is the short-circuit power at individual points in the system, i.e., the impedance of the elements in the supply system. Changes in the value of the supply voltage are caused by changes in voltage drops on the elements of the energy system above the measuring point, i.e., changes in the current flowing through these elements. However, the same changes in current cause smaller changes in the supply voltage when the impedance of the supply circuit is lower, that is, when the short-circuit power at this point is higher [40,41].

The impedances of the system elements and the short-circuit powers were determined based on the rated data and other available information (Appendix A). Table 1 lists the impedances and short-circuit powers behind a given element and the percentage influence of the element on the short-circuit impedance of the entire supply track. The values presented show that about $77 \%$ of the furnace supply path impedance is in the choke, furnace transformer, and high-current track.

Table 1. Calculated values of impedance and short-circuit power in relation to the voltage of $30 \mathrm{kV}$.

\begin{tabular}{cccc}
\hline Element & $\begin{array}{c}\text { Short-Circuit Impedance below the } \\
\text { Power Supply Element } \\
(\mathbf{\Omega})\end{array}$ & $\begin{array}{c}\text { Percentage Share } \\
\mathbf{( \% )}\end{array}$ & $\begin{array}{c}\text { Short-Circuit Power } \\
\text { (MVA) }\end{array}$ \\
\hline $400 \mathrm{kV}$ mains (above TR3) C point & 0.19 & 3.47 & 4750 \\
$110 \mathrm{kV}$ below L1 cable B point & 0.756 & 10.26 & 1191 \\
$30 \mathrm{kV}$ above Choke DL A point & 1.255 & 9.06 & 717 \\
below L2 cable & 2.272 & 8.79 & 396 \\
$1.2 \mathrm{kV}$ below TR_Furnace & 2.757 & 49.93 & 326 \\
$1.2 \mathrm{kV}$ above arc furnace & 5.506 & 163 \\
\hline
\end{tabular}

Long-term measurements of basic power quality indicators were made in the described power supply system at three selected points of the system (A, B, and C) (Figure 1). Figure 2 shows a fragment of the current ( $1 \mathrm{~s}$ RMS values at point $\mathrm{A})$. There are two complete smelting processes with three stages each.

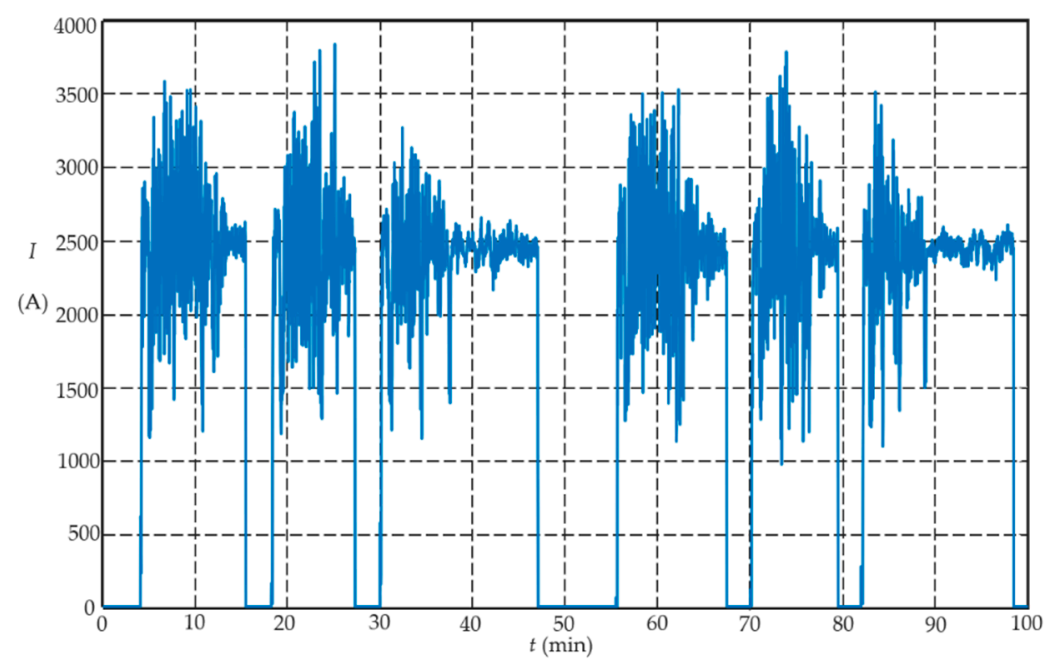

Figure 2. Fragment of the furnace current (1 s RMS) measured at $30 \mathrm{kV}$. 
There are generally three states in the current:

(a) No current-the furnace does not melt;

(b) Highly variable current around $2500 \mathrm{~A}$-the initial melting phase with frequent arc flashover between the electrodes and unmelted elements of the charge;

(c) Current with low variability around $2500 \mathrm{~A}-$ metal in a liquid state.

It is expected that when the current has a high variability there will be high values of the $\mathrm{P}_{\mathrm{st}}$ indicator, whereas when the current has low variability, the values of $\mathrm{P}_{\mathrm{st}}$ will be smaller, and when the furnace does not melt, possible values of $\mathrm{P}_{\mathrm{st}}$ result from the energy background.

\section{Statistical Analysis of Recorded Values of $\mathbf{P}_{\text {st }}$ at Point $\mathbf{A}$}

In the arc furnace supply system (Figure 1 , point $\mathrm{A}$ ) at $30 \mathrm{kV}$, the $\mathrm{P}_{\mathrm{st}}$ indicator was registered, representing the voltage fluctuations resulting from dynamic changes in the load current. Determining the statistical parameters of the $\mathrm{P}_{\text {st }}$ indicator allows quantification of the impact of the arc furnace on the supply network. The short-circuit power at this point, determined based on the impedance model of the power supply system and its components, is 717 MVA.

The basis of the statistical analysis of the $\mathrm{P}_{\mathrm{st}}$ indicator is to make a histogram of the recorded values (Figure 3), on which there are three maxima visible: the first for small values of $\mathrm{P}_{\mathrm{st}}$ (furnace off), the second for a value of $\mathrm{P}_{\mathrm{st}}$ around 3 , and the third for a value of 18 .

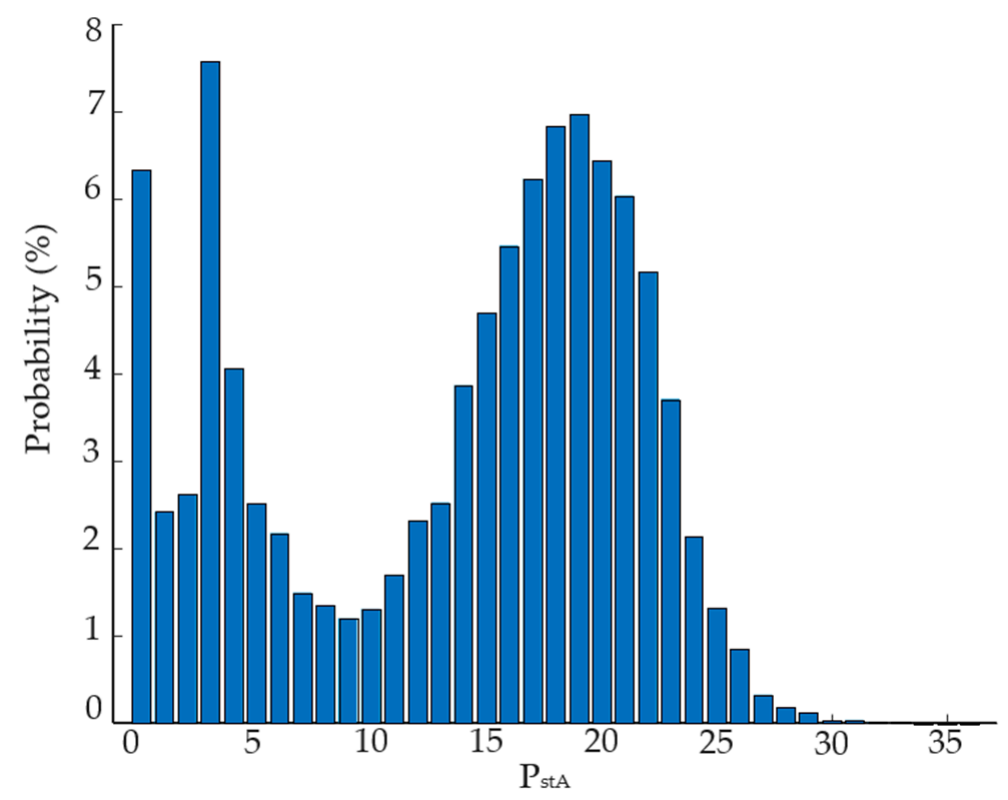

Figure 3. Histogram of recorded values $\mathrm{P}_{\mathrm{st}}$.

The first maximum on the histogram corresponds to the furnace being off. The second and third maxima occur when the furnace melts the charge. The third maximum corresponds to the initial stage of the furnace operation, when the electric arc jumps between the unmelted parts. On the other hand, the second maximum occurs at the liquid phase of the metal. For this article, only the operating range of the furnace is analyzed, i.e., the area of the second and third maxima on the histogram. Figure 4 shows a histogram of the value $P_{\text {st }}$ dedicated to the operation of the furnace.

The criterion of sample separation was to determine the value of $P_{\mathrm{st}}(10 \mathrm{~min})$ in the range wherein the maximum value of the current $(20 \mathrm{~ms})$ did not exceed $200 \mathrm{~A}$. We consider these $P_{\text {st }}$ samples when the furnace has been in operation for a while. The graph also shows the distribution of the histogram. 


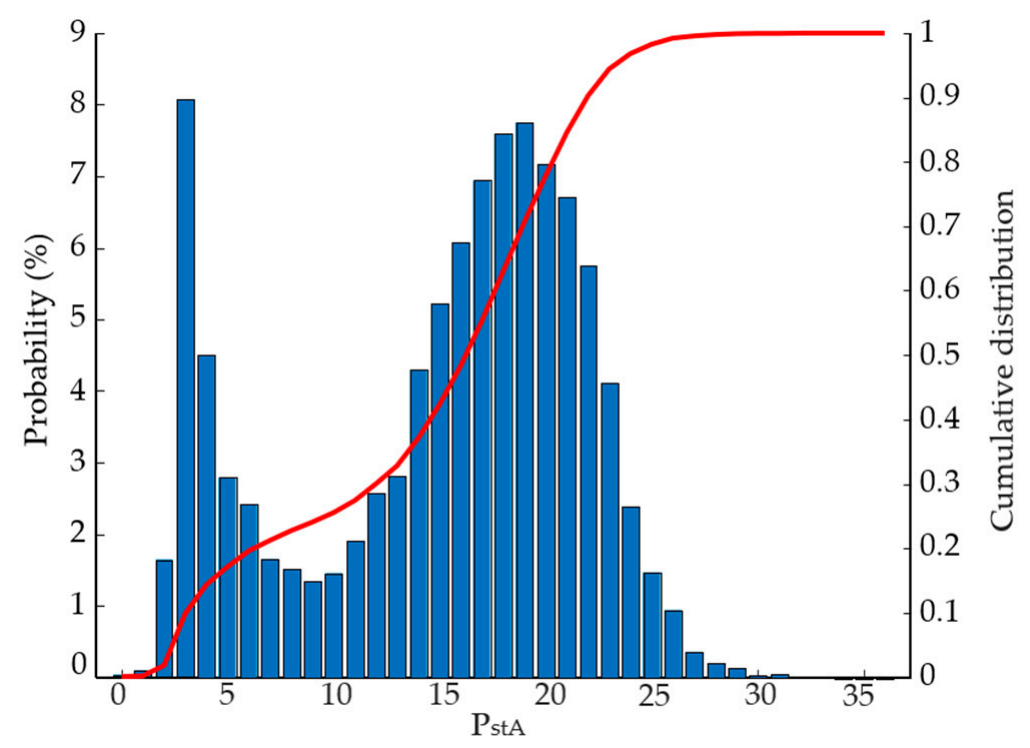

Figure 4. Histogram of $\mathrm{P}_{\mathrm{st}}$ along with a distribution table for an operational furnace.

The histogram in Figure 4 is a combination of two statistical distributions: the generalized distribution of the extreme value (1) and the normal distribution (2). The composition of these distributions is a weighted sum of both processes (3).

$$
y_{1}=f_{1}(z, k, b, c)=c^{-1} \cdot z^{-\frac{1+k}{k}} \cdot \exp \left(-z^{-\frac{1}{k}}\right)
$$

where:

$$
z=\left(1+\frac{k \cdot(x-b)}{c}\right)>0
$$

$x$-random variable

$k$-shape parameter

$b$-location parameter (depending on the average value)

$c$-scale parameter (depending on the standard deviation)

$$
y_{2}=f_{2}(x, \mu, s)=\frac{1}{s \cdot \sqrt{2 \pi}} \exp \left(-\frac{(x-\mu)^{2}}{2 s^{2}}\right)
$$

where:

$x$-random variable

$\mu$-average value

$s-$ standard deviation

$$
y_{3}=(1-a) \cdot y_{1}+a \cdot y_{2}
$$

where $a$ is the standard distribution weighting factor.

Based on the registered values of $P_{s t}$, the function distribution (3) was adjusted by minimizing the maximum difference on the graphs of the distribution of the registered values of $P_{\text {st }}$ and the desired distribution by using the Kolmogorov-Smirnov test (Figure 5). Weight values were sought: $a$ weighted sum, distribution function (3), and parameters of both distributions (1) and (2), i.e., $k, b$, and $c$, and $\mu$ and $s$. The firefly algorithm searched for these values of the decision variables for which the Kolmogorov-Smirnov criterion would be the smallest. It is the task of minimizing the maximum value. 


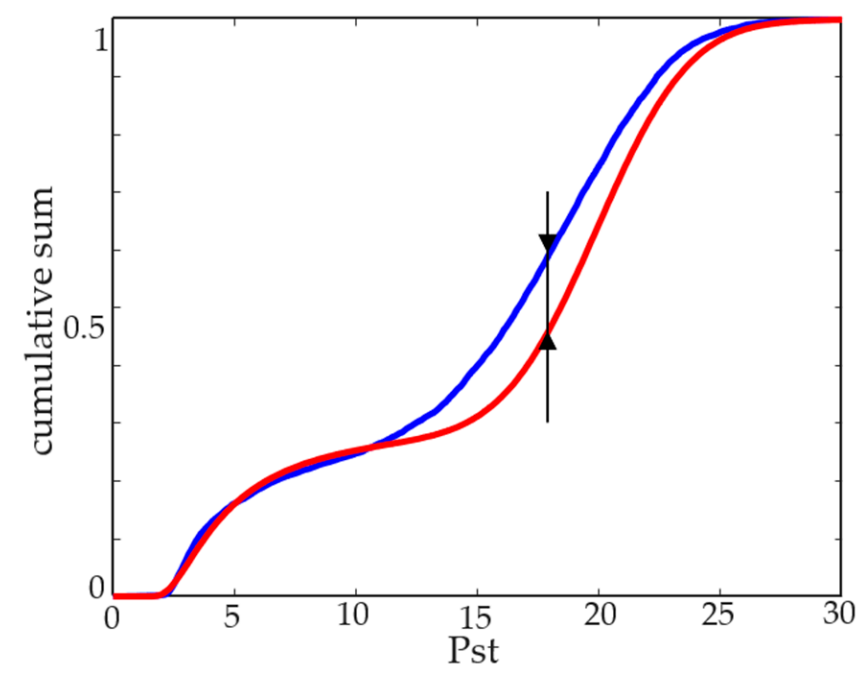

Figure 5. Example of the Kolmogorov-Smirnov test.

Optimization was performed with a modified firefly algorithm $[36,38,39]$. The parameters used in the firefly algorithm follow:

- Number of fireflies: $N=100$;

- Number of iterations: $L_{\text {gene }}=100$;

- Attractiveness factor: $\beta_{0}=2$;

- Light absorption coefficient $\gamma=1$;

- $\quad$ Distance exponent: $m_{1}=1$;

- Mutation coefficient: $\alpha=0.9$;

- $\quad$ Mutation reduction factor: $\alpha_{\text {damp }}=0.9$.

The same parameters of the firefly algorithm were used in all optimization cases in this article, only the allowed ranges of variability of the searched parameters were changed.

Figure 6 shows the optimization result. The indicator $P_{\text {st }}$ histogram is shown with the designated probability distribution (3) (Figure 6a). Figure 6b shows the difference in distribution of the measured $\mathrm{P}_{\text {st }}$ with the matched function (3).

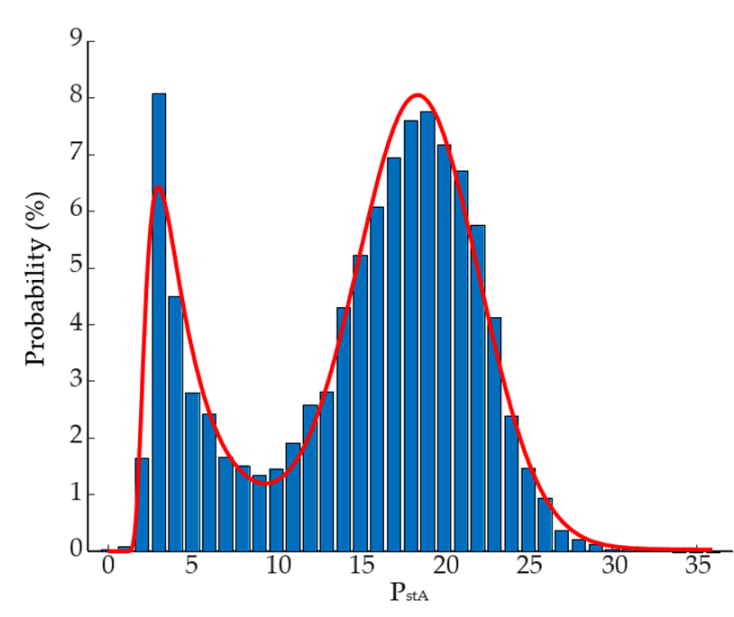

(a)

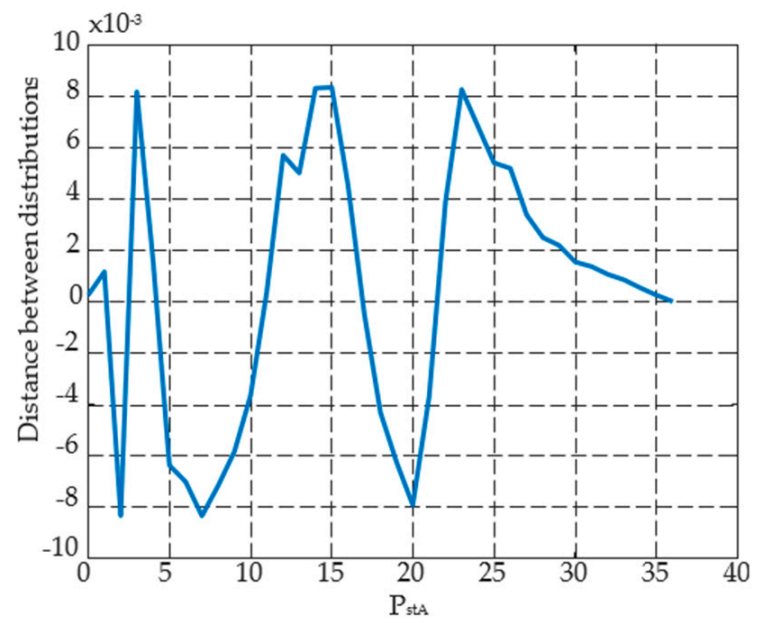

(b)

Figure 6. Adjustment of the $\mathrm{P}_{\mathrm{st}}$ indicator density distribution for a voltage of $30 \mathrm{kV}$ : (a) histogram with the determined distribution, (b) differences between distributions. 
Table 2 summarizes the determined distribution parameters (3).

Table 2. Parameters of the determined distributions.

\begin{tabular}{ccccccc}
\hline \multirow{2}{*}{ Point A } & $\boldsymbol{k}$ & $\boldsymbol{b}$ & $\boldsymbol{c}$ & $\boldsymbol{\mu}$ & $\boldsymbol{s}$ & $\boldsymbol{a}$ \\
\cline { 2 - 7 } & 0.6403 & 3.8444 & 1.9999 & 18.4773 & 3.6000 & 0.7072 \\
\hline
\end{tabular}

The maximum difference between the distribution of the measured $\mathrm{P}_{\mathrm{st}}$ and the fitted distribution is 0.0082; however, it should be remembered that voltage disturbances measured by the $\mathrm{P}_{\text {st }}$ indicator are caused by the operation of the furnace as well as other loads propagating through the system and so, the measured values $\mathrm{P}_{\text {st }}$ at the measuring point are the result of all these causes. The tested arc furnace is both characteristic of and visible in the energy system due to the size of the generated disturbances.

Factor $a$ informs of the division of the measured values $P_{\text {st }}$ between the distributions (1) and (2); $70.72 \%$ of the measurements were included in the normal distribution. The positions of the maxima of the distributions (1) and (2) are described by the values $b=3.8444$ and $\mu=18.4773$, respectively.

\section{Statistical Analysis of Recorded Values $P_{\text {st }}$ at Point $B$}

In the arc furnace supply system (Figure 1), measurements were also taken at point $\mathrm{B}$-level $110 \mathrm{kV}$, synchronously with the measurements taken at point $\mathrm{A}-30 \mathrm{kV}$. The short-circuit power calculated based on the rated data of the transformer and the cable line at this point is 1191 MVA.

It should also be remembered that the arc furnace tested is not the only source of voltage disturbances in this system. Other ladle and arc furnaces are supplied from the $110 \mathrm{kV}$ level, but are of lower power, together with other accompanying devices.

Figure 7a shows a histogram of the value $\mathrm{P}_{\text {st }}$ at point $B$. Similarly to point $A$, the probability distribution was fitted using a modified firefly algorithm. The optimization criterion was to minimize the Kolmogorov-Smirnov test, i.e., to minimize the maximum difference between the distribution function of the measured $\mathrm{P}_{\mathrm{st}}$ and the matched distribution. The distribution difference diagram is shown in Figure $7 \mathrm{~b}$.

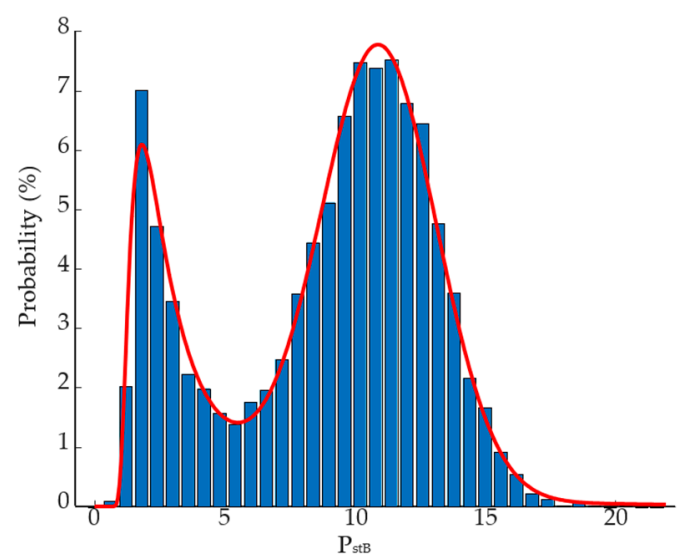

(a)

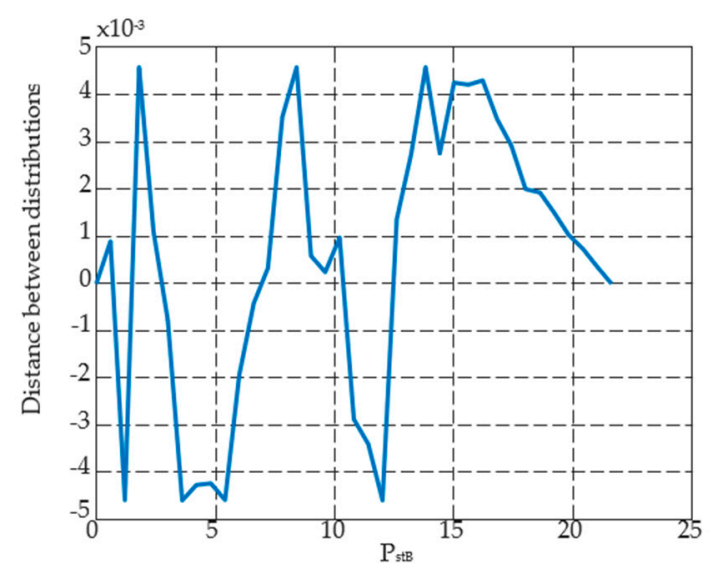

(b)

Figure 7. Adjustment of the $\mathrm{P}_{\text {st }}$ indicator density for a distribution of voltage of $110 \mathrm{kV}$ : (a) histogram with the determined distribution, (b) differences between distributions.

The maximum difference in distribution of the measured $\mathrm{P}_{\mathrm{st}}$ and the fitted distribution is 0.0046 .

The histograms in Figures 6a and 7a (for points A and B) are similar in shape, differing mainly in the location of the maxima. The histogram in Figure 7a is narrower (compressed in the $\mathrm{Y}$ direction) compared to the histogram in Figure 6a. Table 3 summarizes the param- 
eters characterizing the density distributions for points $\mathrm{A}$ and $\mathrm{B}$. The second maximum (value $\mu$ ) shifted from 18.4773 to 10.9085 , which is $59 \%$ of the initial value. The first maximum (value $b$ ) shifted from 3.8444 to 2.3243 , which is $60.46 \%$ of the initial value. The values decrease in a similar way for $c$ and $s$.

Table 3. The values characterizing the density distributions for points A and B.

\begin{tabular}{ccccccc}
\hline & $\boldsymbol{k}$ & $\boldsymbol{b}$ & $\boldsymbol{c}$ & $\boldsymbol{\mu}$ & $\boldsymbol{s}$ & $\boldsymbol{a}$ \\
\hline Point A & 0.6403 & 3.8444 & 1.9999 & 18.4773 & 3.6000 & 0.7072 \\
\hline Point B & 0.5759 & 2.3243 & 1.1993 & 10.9085 & 2.2600 & 0.7132 \\
\hline B/A & 0.8994 & 0.6046 & 0.5997 & 0.5904 & 0.6278 & 1.0085 \\
\hline
\end{tabular}

It is also worth noting that some values in the " $\mathrm{B} / \mathrm{A}$ " row of Table 3 correspond to the ratio of the calculated short-circuit power (Table 1) at the measurement points (5).

$$
d_{\mathrm{AB}}=\frac{S_{\mathrm{A}}}{S_{\mathrm{B}}}=\frac{717}{1191}=0.602
$$

This value results from the impedance of the supply track. Indicator $d_{\mathrm{AB}}$ (voltage disturbance propagation indicator) is the quotient of the short-circuit impedance at point $\mathrm{B}$ to the short-circuit impedance at point A (6).

$$
d_{\mathrm{AB}}=\frac{Z_{\mathrm{B}}}{Z_{\mathrm{A}}}=\frac{0.756}{1.235}=0.602
$$

As already mentioned, the value of $d_{\mathrm{AB}}$ can be seen in Table 3 in row " $\mathrm{B} / \mathrm{A}$ " for value $b, c, \mu$, and $s$. Additional information about the nature of the histogram changes can be formulated based on the dependence graph of the recorded values of $P_{s t}$ at the level of $110 \mathrm{kV}$ from the value of $P_{\text {st }}$ registered at the $30 \mathrm{kV}$ level (Figure 8). Approximations of measurements of $\mathrm{P}_{\mathrm{st}}$ can be made with a straight line with an inclination of 0.5978 . The same value was obtained by calculating the mean value of the quotient $\mathrm{P}_{\mathrm{stB}} / \mathrm{P}_{\mathrm{stA}}$.

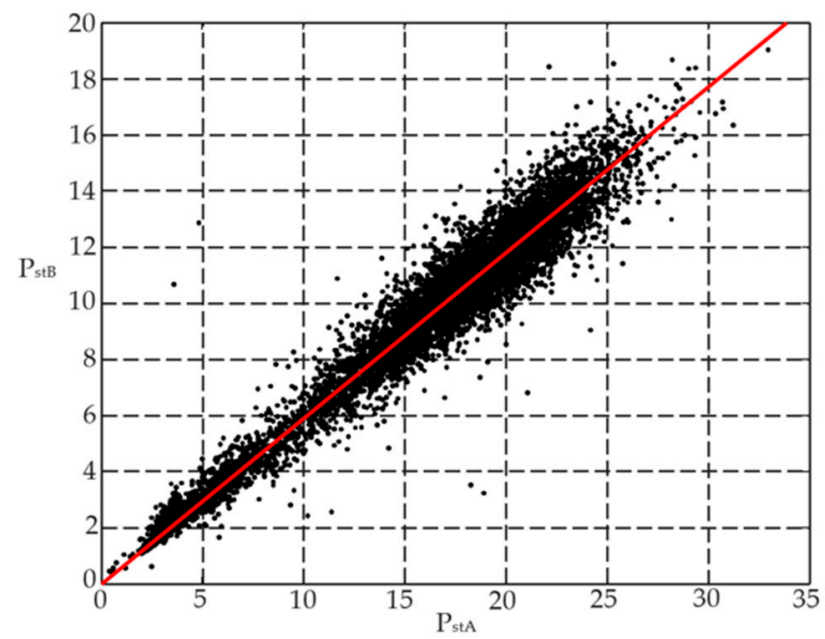

Figure 8. Graph of relationship between indicators of $P_{s t}$ measured at point $B$ and those measured at point $\mathrm{A}$, and the approximating line.

The data presented shows that it is possible to estimate the short-circuit impedance at the measuring point (and thus the short-circuit power) based on the value $\mathrm{P}_{\mathrm{st}}$ at both points and the impedance between the points $Z_{\mathrm{AB}}$ (7).

$$
Z_{\mathrm{B}}=\frac{d_{\mathrm{AB}}}{1-d_{\mathrm{AB}}} Z_{\mathrm{AB}} ; Z_{\mathrm{A}}=\frac{1}{1-d_{\mathrm{AB}}} Z_{\mathrm{AB}}
$$


Therefore, the short-circuit power at the test point can be estimated from (8).

$$
S_{\mathrm{B}}=\frac{\left(1-d_{\mathrm{AB}}\right)}{d_{\mathrm{AB}}} \cdot \frac{U^{2}}{Z_{\mathrm{AB}}} ; S_{\mathrm{A}}=\left(1-d_{\mathrm{AB}}\right) \cdot \frac{U^{2}}{Z_{\mathrm{AB}}}
$$

On the basis of Formulas (7) and (8), the impedance between points $\mathrm{A}$ and $\mathrm{B}$ $\left(Z_{\mathrm{AB}}=0.499 \Omega\right)$ and the determined propagation coefficient of voltage disturbances $d_{\mathrm{AB}}=0.5904$ (value $\mu$ from Table 3 ), short-circuit power was calculated in various measuring points of the power supply system $\left(S_{\mathrm{A}}=739 \mathrm{MVA}, S_{\mathrm{B}}=1251 \mathrm{MVA}\right)$ and short circuit impedance at these points $\left(Z_{A}=1.218 \Omega, Z_{B}=0.719 \Omega\right)$. The calculated values are close to the values in Table 1.

\section{Statistical Analysis of Recorded Values $P_{\text {st }}$ at Point $C$}

In the arc furnace supply system (Figure 1), measurements were taken at point Clevel $400 \mathrm{kV}$, synchronously with the measurements at points A-30 kV and B-110 kV. The short-circuit power of point $C$ is 4750 MVA (according to the technical documentation).

Figure 9a shows the relationship between the recorded values of $P_{s t}$ at point $C$ and the value of $P_{s t}$ at point $B$, and in Figure $9 b$, the relationship between the quotient $P_{s t C} / P_{s t B}$ and the value of $P_{s t}$ from point $B$.

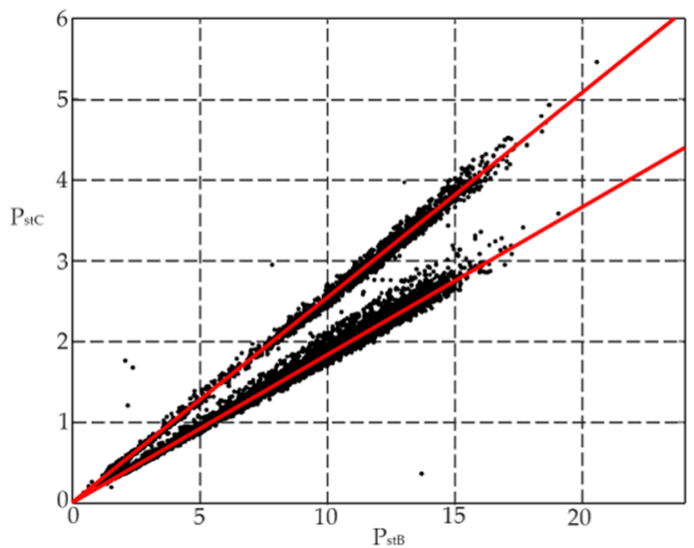

(a)

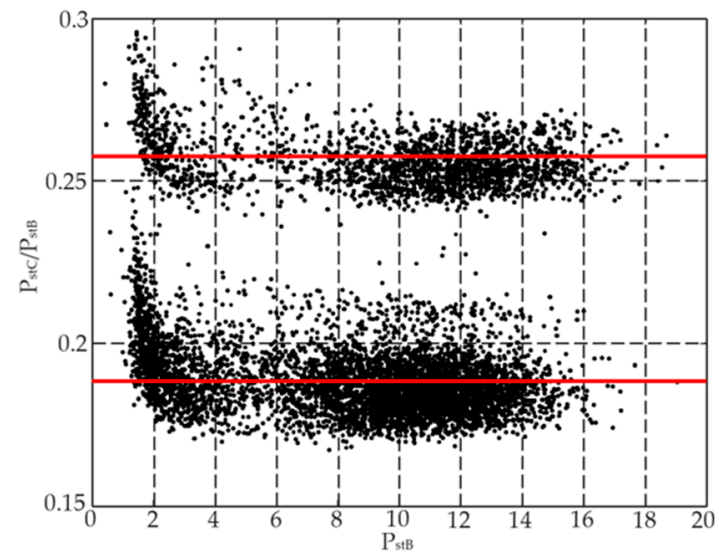

(b)

Figure 9. Relationship between: (a) the values of the $P_{s t}$ indicatorat points $C$ and $B,(b)$ the quotient $P_{s t C} / P_{s t B}$ and the value of $\mathrm{P}_{\text {st }}$ from point $\mathrm{B}$.

Figure 9 shows that the short-circuit impedance at point $C$, and thus the short-circuit power, changed during the measurement process. Two groups of points distributed along two approximating lines are clearly visible. At points A and B, this difference was not visible due to the low value of the short-circuit impedance of the network in relation to the short-circuit impedance at points A and B. It can be presumed that during the operation of the furnace there were configuration changes in the supply network. Therefore, it is necessary to separate the two cases of furnace operation in order to be able to identify both short-circuit impedances. The mean value of the points of the lower group (Figure $9 b$ ) and the inclination of the lower approximating line (Figure 9a) is 0.1885 ; for the higher group, it is 0.2575 .

Using the modified firefly algorithm, the probability distributions for both furnace operation cases were determined. Figure 10 shows the histograms and distribution differences for these cases.

Searching for the matching of the distributions, the values of the Kolmogorov-Smirnov test were obtained for two furnace operation cases: 0.0071 and 0.0047 , respectively. Table 4 presents the parameters of the fitted distributions and the ratios of these values to the values obtained for the measurement point $B$ and $A$. 


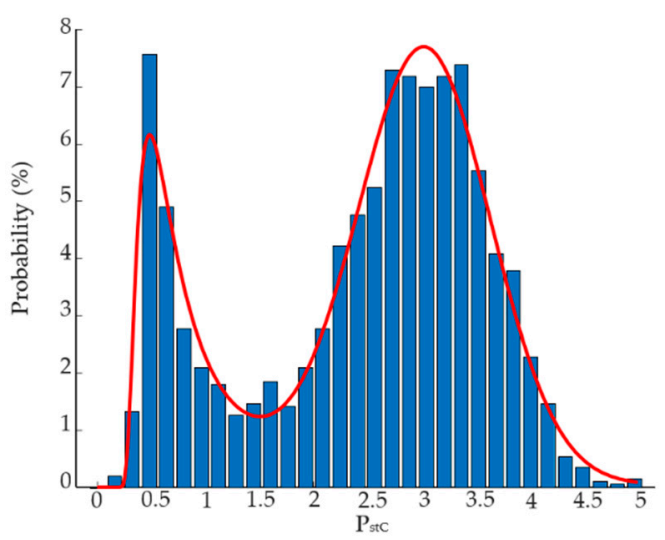

(a)

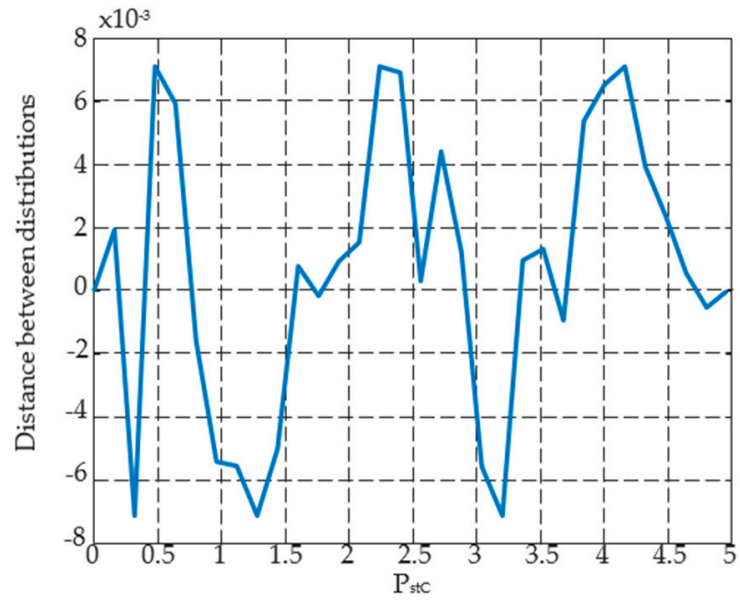

(c)

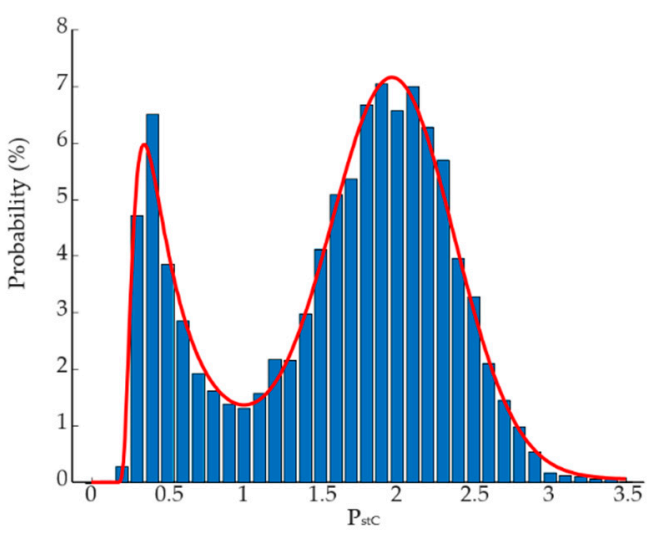

(b)

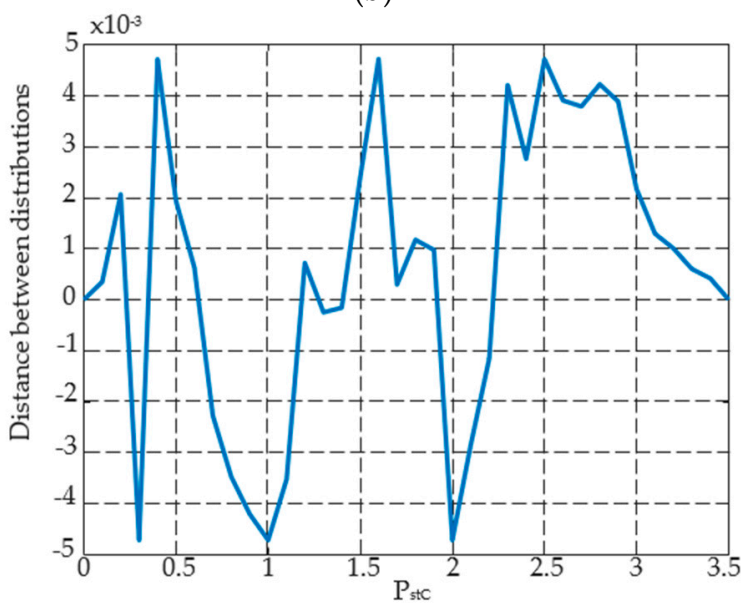

(d)

Figure 10. Histograms of two furnace conditions $(\mathbf{a}, \mathbf{b})$ and graphs of differences in distribution functions of the measured values $\mathrm{P}_{\mathrm{st}}$ and determined distributions $(\mathbf{c}, \mathbf{d})$.

Table 4. The values characterizing the density distributions for points $\mathrm{A}, \mathrm{B}$, and $\mathrm{C}$.

\begin{tabular}{ccccccc}
\hline & $\boldsymbol{k}$ & $\boldsymbol{b}$ & $\boldsymbol{c}$ & $\boldsymbol{\mu}$ & $\boldsymbol{s}$ & $\boldsymbol{a}$ \\
\hline Point A & 0.6403 & 3.8444 & 1.9999 & 18.4773 & 3.6000 & 0.7072 \\
Point B & 0.5759 & 2.3243 & 1.1993 & 10.9085 & 2.2600 & 0.7132 \\
Point C_1 & 0.6591 & 0.6201 & 0.3209 & 2.911 & 0.6054 & 0.7141 \\
Point C_2 & 0.7207 & 0.451 & 0.2362 & 1.9919 & 0.4139 & 0.6956 \\
B/A & 0.8994 & 0.6046 & 0.5997 & 0.5904 & 0.6278 & 1.0085 \\
C_1/B & 1.1445 & 0.2668 & 0.2676 & $\mathbf{0 . 2 6 6 9}$ & 0.2679 & 1.0013 \\
C_2/B & 1.2514 & 0.1940 & 0.1969 & $\mathbf{0 . 1 8 2 6}$ & 0.1831 & 0.9753 \\
C_1/A & 1.0294 & 0.1613 & 0.1605 & 0.1575 & 0.1682 & 1.0098 \\
C_2/A & 1.1256 & 0.1173 & 0.1181 & 0.1078 & 0.1150 & 0.9836 \\
\hline
\end{tabular}

Based on the values in Table 4, the value of the voltage disturbance propagation factor $d_{\mathrm{BC}}$ was assumed to be 0.2669 and 0.1826 (column $\mu$ ), and the resulting impedance and short-circuit power values (7) and (8) for the impedance between points $B$ and $C\left(Z_{B C}=\right.$ $0.565 \Omega$ ) are 0.2057 and $0.1262 \Omega$, and 4375 and 7131 MVA, respectively. During operation, the furnace was powered for $75 \%$ of the time from the network, with a short-circuit power of 7131 MVA.

Table 4 also presents the quotients of the distribution parameters for individual points. It is not surprising that the coefficient of voltage disturbance propagation between points $\mathrm{A}$ and $C$ is the product of the coefficient of voltage disturbance propagation between points $A$ and $B$, and $B$ and $C(9)$.

$$
d_{\mathrm{AC}}=d_{\mathrm{AB}} \cdot d_{\mathrm{BC}}
$$


At point $C$, the values of $P_{\text {st }}$ reach $15.75 \%$ or $10.78 \%$ of the value $P_{\text {st }}$ at point $A$, depending on the configuration of the supply network. This means that there will be less fluctuation in the supply network when the impedance of the supply track from point C to the furnace is greater than the impedance above that point. The degree of damping of fluctuations is determined by the ratio of the impedance above the supply point to the track impedance below the point considered.

The reduction of voltage fluctuations between two points of the supply network, $d_{\mathrm{AB}}$, depends on the equivalent impedance of this grid fragment (10).

$$
d_{\mathrm{AB}}=1-\frac{S_{A} \cdot Z_{\mathrm{AB}}}{U^{2}}
$$

\section{Conclusions}

Using the example of the arc furnace, which is a large, turbulent load significantly different from other loads in the supply network, it was possible to observe the propagation of voltage disturbances in the supply network. The measure of these disorders is the indicator $P_{\text {st }}$, the values of which decrease with the distance from the source of disturbances. The degree of reduction of these values is determined by the voltage disturbance propagation indicator, $d$, determined for a given section of the supply network. This value depends on the equivalent impedance of a given section (10) or the ratio of impedances (6), or the ratio of short-circuit power (5).

The short-circuit impedance or the short-circuit power at another point in the power system can be determined from the relationships (7) and (8), knowing the voltage disturbance propagation coefficient. The propagation factor of voltage disturbances between two points in the network can also be estimated based on the measured values $P_{\text {st }}$ at these points by determining the angle of inclination of the line approximating the relationship $\mathrm{P}_{\mathrm{stB}} / \mathrm{P}_{\mathrm{stA}}$. Another possibility for estimating the propagation value of voltage disturbances is provided by the analysis of statistical processes and estimating the characteristic parameters of the probability distributions, i.e., the location of the distribution maxima and the width of these distributions; in the example presented, these are the values $b, c, \mu$, and $s$.

The influence of a given load on the supply network at a given point decreases with the increase of the short-circuit power at that point (i.e., with the decrease of the shortcircuit impedance). The greater short-circuit power at the measuring point, the smaller the $P_{\text {st }}$ values. This means that the reduction of the $P_{\text {st }}$ value is greater when the quotient of the short-circuit impedance at the load connection point to the short-circuit impedance at the measuring point (the measuring point is above the load connection point) is greater.

Funding: This research received no external funding.

Conflicts of Interest: The authors declare no conflict of interest.

\section{Appendix A}

Parameters of the elements of the energy system:

Transformer TR3-Yy0d11

$U_{1 \mathrm{~N}}=400 \mathrm{kV}$

$U_{2 \mathrm{~N}}=113.775 \mathrm{kV}$

$U_{3 \mathrm{~N}}=31.5 \mathrm{kV}$

$S_{\mathrm{N}}=250 \mathrm{MVA}, 250 \mathrm{MVA}, 50 \mathrm{MVA}$

$\Delta P_{\mathrm{Fe}}=226.95 \mathrm{~kW}$

$\Delta P_{\mathrm{Cu}}=830.34 \mathrm{~kW}, \mathrm{GN} / \mathrm{DN} 1$

$i_{0 \%}=0.5 \%$

$u_{1 \%}=14.96 \%, \mathrm{GN} / \mathrm{DN} 1$

$u_{2 \%}=12.20 \%, \mathrm{GN} / \mathrm{DN} 2$

$u_{3 \%}=8.92 \%, \mathrm{DN} 1 / \mathrm{DN} 2$

$I_{1 \mathrm{~N}}=361 \mathrm{~A}$ 


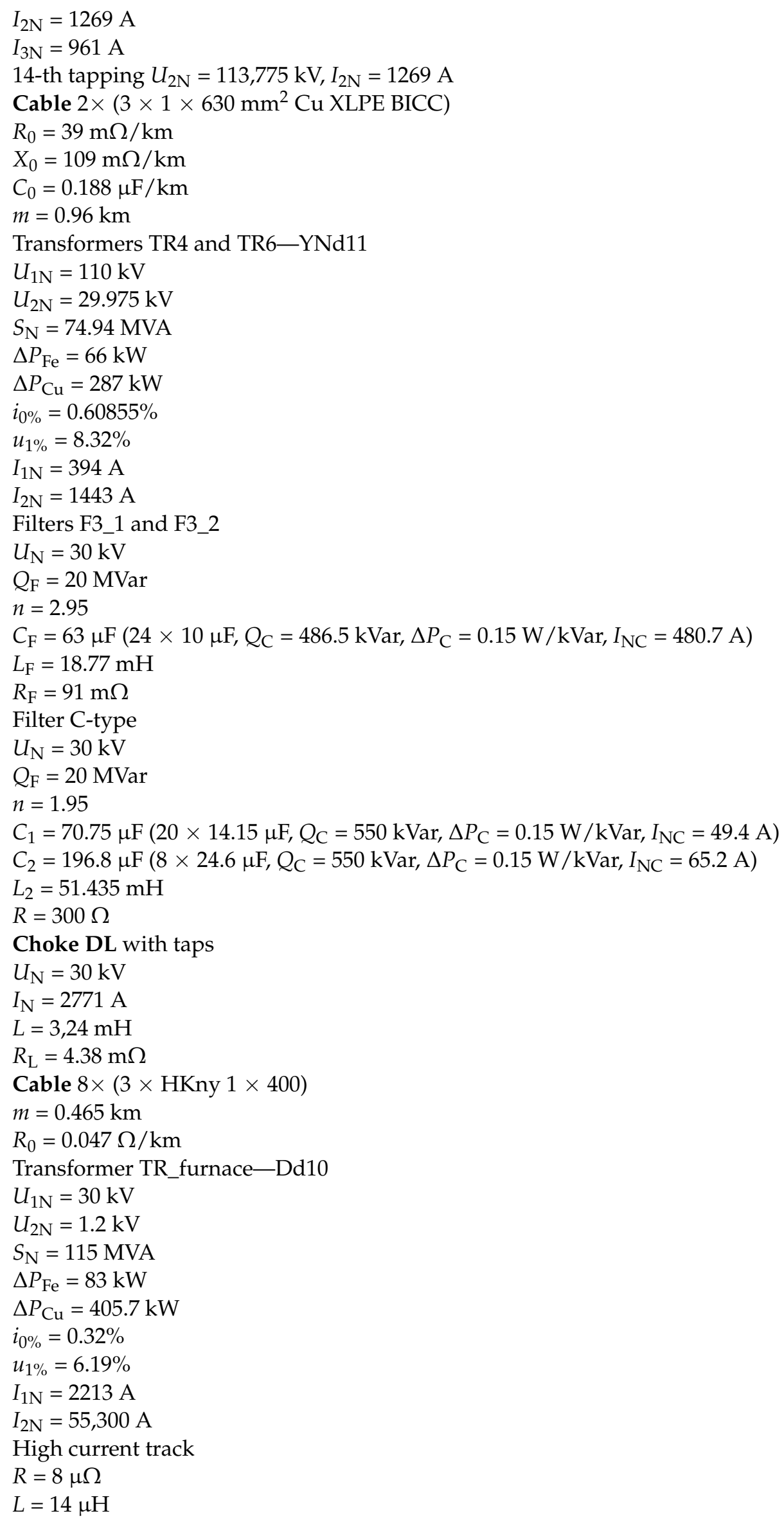




\section{References}

1. NSAI. Voltage Characteristics of Electricity Supplied by Public Electricity Networks; EN 50160; National Standards Authority of Ireland: Nashua, NH, USA, 2014.

2. Nassif, A.; Nino, E.; Xu, W. A V-I slope-based method for flicker source detection. In Proceedings of the 37th Annual North American Power Symposium, Ames, IA, USA, 25 October 2005; pp. 364-367. [CrossRef]

3. Hernandez, A.; Mayordomo, J.G.; Asensi, R.; Beites, L.F. A Method Based on Interharmonics for Flicker Propagation Applied to Arc Furnaces. IEEE Trans. Power Deliv. 2005, 20, 2334-2342. [CrossRef]

4. Axelberg, P.; Bollen, M. An Algorithm for Determining the Direction to a Flicker Source. IEEE Trans. Power Deliv. 2006, 21, 755-760. [CrossRef]

5. Hanzelka, Z.; Słupski, P.; Piątek, K.; Warecki, J.; Zielinski, M. Single-Point Methods for Location of Distortion, Unbalance, Voltage Fluctuation and Dips Sources in a Power System. In Power Quality-Monitoring, Analysis and Enhancement; IntechOpen: London, UK, 2011; pp. 157-198.

6. Mróz, M.; Chmielowiec, K.; Hanzelka, Z. Voltage fluctuations in networks with distributed power sources. In Proceedings of the 2012 IEEE 15th International Conference on Harmonics and Quality of Power, Hong Kong, China, 17-20 June 2012; pp. 920-925.

7. Maksic, M.; Papic, I.; Blažič, B. Simple Continuous Assessment of Transmission-Network Flicker Levels Caused by Multiple Sources. IEEE Trans. Power Deliv. 2015, 31, 2546-2552. [CrossRef]

8. Saleh, S.A. Phaselet Transform Based Approach for Detecting Voltage Flickers Due to Distributed Generation Units. IEEE Trans. Ind. Appl. 2017, 54, 5278-5292. [CrossRef]

9. Saadat, A.; Hooshmand, R.-A.; Tadayon, M. Flicker Propagation Pricing in Power Systems Using a New Short-Circuit-Based Method for Determining the Flicker Transfer Coefficient. IEEE Trans. Instrum. Meas. 2021, 70, 1-9. [CrossRef]

10. Yang, X.; Papic, I. Study of flicker propagation in electric grid by modeling and on-site flicker measurements. In Proceedings of the IEEE PES General Meeting, Minneapolis, MN, USA, 25-29 July 2010; pp. 1-5. [CrossRef]

11. Maksic, M.; Blazič, B.; Papic, I. Flicker summation factor in the slovenian transmission network. In Proceedings of the 2011 IEEE Trondheim PowerTech, Trondheim, Norway, 19-23 June 2011; pp. 1-6. [CrossRef]

12. Olay, C.C.; Fernandez, S.M.; Bayo, A.H.; Rodríguez, J.C.C.; García, S.M. Synthesis and Evaluation of Fast Onload Multitap Changers for Flicker Compensation in AC Arc Furnaces. IEEE Trans. Power Deliv. 2014, 29, 2519-2527. [CrossRef]

13. Marcus, I.U.; Cepisca, C. On the influence of network impedance on flicker measurements. In Proceedings of the 201710 th International Symposium on Advanced Topics in Electrical Engineering (ATEE), Bucharest, Romania, 23-25 March 2017 ; pp. 836-841. [CrossRef]

14. IEC. Electromagnetic Compatibility (EMC)—Part 4-15: Testing and Measurement Techniques_Flickermeter—Functional and Design Specifications; EN 61000-4-15; International Electrotechnical Commission: Geneva, Switzerland, 2010.

15. Maksic, M.; Papic, I. Analysis of Flicker Propagation with Representative Samples of Network Voltage. IEEE Trans. Power Deliv. 2011, 26, 2066-2067. [CrossRef]

16. Hsu, Y.-J.; Chen, K.-H.; Huang, P.-Y.; Lu, C.-N. Electric Arc Furnace Voltage Flicker Analysis and Prediction. IEEE Trans. Instrum. Meas. 2011, 60, 3360-3368. [CrossRef]

17. Eghtedarpour, N.; Farjah, E.; Khayatian, A. Effective Voltage Flicker Calculation Based on Multiresolution S-Transform. IEEE Trans. Power Deliv. 2012, 27, 521-530. [CrossRef]

18. Albistur, C.F.; Aravena, P.A.; Moran, L.A.; Espinoza, J.R. A Simple Predictive Method to Estimate Flicker. IEEE Trans. Ind. Appl. 2013, 50, 2150-2155. [CrossRef]

19. Yao, W.; Tang, Q.; Teng, Z.; Gao, Y.; Wen, H. Fast S-Transform for Time-Varying Voltage Flicker Analysis. IEEE Trans. Instrum. Meas. 2013, 63, 72-79. [CrossRef]

20. Hsu, Y.-J.; Lu, C.-N. Statistical Analyses of $\mathrm{P}_{\mathrm{st}}$ and $\Delta \mathrm{V}_{10}$ Recorded at Electric Arc Furnaces. IEEE Trans. Power Deliv. 2013, 29, 1508-1510. [CrossRef]

21. Srdic, S.; Nedeljkovic, M.; Vukosavic, S.N.; Radakovic, Z. Fast and Robust Predictive Current Controller for Flicker Reduction in DC Arc Furnaces. IEEE Trans. Ind. Electron. 2016, 63, 4628-4640. [CrossRef]

22. Geiger, D.L.; Halpin, S.M. Assessing Voltage Fluctuations and Lamp Flicker Using RMS Voltages. IEEE Trans. Power Deliv. 2017, 32, 2481-2488. [CrossRef]

23. Liang, Y.; Ma, X.; Zhao, F.; Hao, S.; Du, S.; Su, J.; Zhang, Y.; Zhao, T. A High Accuracy Detection Method of Voltage Flicker Signal Based on Time-Frequency Transform. In Proceedings of the 2019 9th International Conference on Power and Energy Systems (ICPES), Perth, Australia, 10-12 December 2019; pp. 1-5.

24. Alawadhi, N.; Elnady, A. Estimation and Mitigation of Voltage Flicker Using Extended Complex Kalman Filter. In Proceedings of the 2020 Advances in Science and Engineering Technology International Conferences (ASET), Dubai, UAE, 4 February-9 April 2020; pp. 1-6.

25. Xia, R.; Gao, Y.; Li, C.; Wu, C.; Wang, C. Simplified and fast method without considering filter for voltage flicker detection. IET Gener. Transm. Distrib. 2020, 14, 3260-3268. [CrossRef]

26. Borkowski, D.; Barczentewicz, S. Power Grid Impedance Tracking with Uncertainty Estimation Using Two Stage Weighted Least Squares. Metrol. Meas. Syst. 2014, 21, 99-110. [CrossRef] 
27. Bhonsle, D.C.; Kelkar, R.B. Simulation of electric arc furnace characteristics for voltage flicker study using MATLAB. In Proceedings of the 2011 International Conference on Recent Advancements in Electrical, Electronics and Control Engineering, Sivakasi, India, 15-17 December 2011; pp. 174-181.

28. Klempka, R. Design of C-type passive filter for ARC furnaces. Metalurgija 2017, 56, 161-163.

29. Lange, A.G.; Redlarski, G. Selection of C-Type Filters for Reactive Power Compensation and Filtration of Higher Harmonics Injected into the Transmission System by Arc Furnaces. Energies 2020, 13, 2330. [CrossRef]

30. Duda, K.; Zielinski, T.P.; Bien, A.; Barczentewicz, S.H. Harmonic Phasor Estimation with Flat-Top FIR Filter. IEEE Trans. Instrum. Meas. 2019, 69, 2039-2047. [CrossRef]

31. Wetula, A.; Bień, A. New Measures of Power-Grid Voltage Variation. IEEE Trans. Power Deliv. 2014, 29, 1020-1027. [CrossRef]

32. He, N.; Xu, D.; Huang, L. The Application of Particle Swarm Optimization to Passive and Hybrid Active Power Filter Design. IEEE Trans. Ind. Electron. 2009, 56, 2841-2851. [CrossRef]

33. Verma, V.; Singh, B. Genetic-Algorithm-Based Design of Passive Filters for Offshore Applications. IEEE Trans. Ind. Appl. 2010, 46, 1295-1303. [CrossRef]

34. Sirjani, R.; Kusaf, M. Optimal design of passive harmonic filters using Bee Colony Optimization. In Proceedings of the 2016 HONET-ICT, Nicosia, Cyprus, 13-14 October 2016; pp. 88-92.

35. Fahmy, M.A.; Ibrahim, A.M.; Baici, M.E.; Aleem, S.H.E.A. Multiobjective optimization of double-tuned filters in distribution power systems using non-dominated sorting genetic algorithm-II. In Proceedings of the 2017 10th International Conference on Electrical and Electronics Engineering (ELECO), Bursa, Turkey, 30 November-2 December 2017; pp. $195-200$.

36. Klempka, R.; Waradzyn, Z.; Skala, A. Application of the Firefly Algorithm for Optimizing a Single-switch Class E ZVS VoltageSource Inverter's Operating Point. Adv. Electr. Comput. Eng. 2018, 18, 93-100. [CrossRef]

37. Aleem, S.H.E.A.; Zobaa, A.F.; Balci, M.E.; Ismael, S.M. Harmonic Overloading Minimization of Frequency-Dependent Components in Harmonics Polluted Distribution Systems Using Harris Hawks Optimization Algorithm. IEEE Access 2019, 7, 100824-100837. [CrossRef]

38. Klempka, R. Optimal Double-Tuned Filter Efficiency Analysis. IEEE Trans. Power Deliv. 2020, 1. [CrossRef]

39. Klempka, R. Modification of the Firefly Algorithm for Improving Solution Speed. In Advances in Intelligent Systems and Computing; Springer: Berlin, Germany, 2020; Volume 1196, pp. 115-124.

40. UIEPQ-9715. Guide to Quality of Electrical Supply for Industrial Installations, Part 5: Flicker and Voltage Fluctuations, Union Internationale de Electrothermie (UIE), 1999.

41. Hanzelka, Z. Jakość Dostawy Energii Elektrycznej; (The quality of electric power supply); Wydawnictwa AGH: Krakow, Poland, 2013. (In Polish) 